\title{
Diagnóstico Quali-Quantitativo da Arborização Viária de Campo Mourão, Paraná
}

\author{
Qualitative and Quantitative Diagnosis of Street Afforestation in Campo Mourão, \\ Paraná
}

\section{Diagnóstico Cuali-Cuantitativo de la Arborización Vial de Campo Mourão, Paraná}

\author{
Guilherme Junges Leme ${ }^{1}$ \\ https://orcid.org/0000-0002-1538-4938 \\ Marcos Clair Bovo ${ }^{2}$ \\ https://orcid.org/0000-0003-3582-6702 \\ Ana Paula Colavite ${ }^{3}$ \\ https://orcid.org/0000-0003-2113-4844
}

\begin{abstract}
RESUMO: A arborização urbana viária é fundamental para a manutenção da qualidade de vida, visto que proporciona conforto aos habitantes das cidades, porém a ausência de planejamento tem causado problemas, principalmente relacionados à implantação e ao manejo da arborização em vias públicas. A pesquisa objetiva caracterizar e analisar a arborização viária no centro da cidade de Campo Mourão/PR, evidenciando a percepção dos moradores. O aporte metodológico teve por base levantamento quali-quantitativo das árvores por meio do aplicativo de celular Mapit, posteriormente foram inseridos no Google Earth Pro e exportados para o ArcGis para a elaboração dos mapas temáticos sobre a realidade arbórea do município. Os formulários foram disponibilizados para a população através da rede social Facebook. Os resultados obtidos por meio do mapeamento registraram 571 árvores, a maioria não apresentou conflitos e as que apresentaram foram principalmente em relação à fiação elétrica e calçada. $O$ questionário apontou um conhecimento parcial sobre o tema e a maioria dos entrevistados demonstrou interesse em participar ativamente das decisões políticas relacionadas ao assunto e, até mesmo, em sua manutenção e conservação.
\end{abstract}

PALAVRAS-CHAVE: Vegetação urbana. Quali-quantitativo. Percepção. Distribuição espacial. Elementos urbanos.

\footnotetext{
${ }^{1}$ Graduado em Turismo e Meio Ambiente, Universidade Estadual do Paraná, Campus de Campo Mourão. Email: guijungesleme@gmail.com.

${ }^{2}$ Doutor em Geografia (UNESP). Professor Associado da Universidade Estadual do Paraná, Campus de Campo Mourão. E-mail: mcbovo69@gmail.com.

${ }^{3}$ Doutora em Geografia (UEM), Professora Adjunta da Universidade Estadual do Paraná, Campus de Campo Mourão. E-mail: ana.colavite@ies.unespar.edu.br.
} 


\begin{abstract}
The urban afforestation of streets is of first importance for the maintenance of life quality, providing comfort for the citizens. However, the lack of planning has been causing problems, mainly related to the implementation and management of urban streets' afforestation. This research aims at characterizing and analyzing streets' afforestation in the central area of Campo Mourão/PR, highlighting the perception of residents. Methodological approach was based on a qualitative and quantitative survey on the trees performed with the mobile app Mapit, further transferred to Google Earth Pro and exported to ArcGis, as means for the production of thematic maps showing the reality of trees in the city. Forms were sent to the citizens through Facebook. Results of the mapping have registered 571 trees, most of it without conflicts. The ones with conflicts were mainly related to electric wiring and sidewalks. The questionnaire indicates a partial knowledge on the subject, and most respondents show interest both in taking an active role in political decisions related to it and helping with the maintenance and preservation.
\end{abstract}

KEYWORDS: Urban vegetation. Qualitative and quantitative. Perception. Spatial distribution. Urban elements.

RESUMEN: La vegetación a lo largo de las calles públicas compone la forestación urbana y proporciona calidad de vida a la población, sin embargo, si las especies elegidas y su manejo no son adecuados, pueden causar daños y perturbaciones. Esta investigación tuvo como objetivo analizar la forestación de las calles de Campo Mourão/PR, centrándose cualitativamente en la opinión de la población sobre el tema, observando los posibles conflictos de los árboles con otros elementos urbanos y cuantitativamente en lo que respecta al número de árboles y su distribución en el espacio delimitado. Los procedimientos incluyeron pasos de recolección de datos de campo para el mapeo de las especies de árboles y la evaluación de los conflictos relacionados con los especímenes plantados, así como la aplicación de un cuestionario en línea para verificar la percepción de la población sobre el tema. En el mapeo se registraron 571 árboles, la mayoría de los cuales no presentaban conflictos, y los que sí los presentaban estaban relacionados principalmente con el cableado eléctrico y la acera. El cuestionario puso de manifiesto un conocimiento parcial del tema y la mayoría de los entrevistados mostraron interés en participar activamente en las decisiones políticas relativas al tema e incluso en su mantenimiento y conservación. Se considera que la investigación obtuvo información importante para el diálogo entre la población y el poder público sobre la forestación de las calles.

PALABRAS CLAVE: Vegetación urbana. Cualitativa y cuantitativa. Percepción de la población. Distribución espacial. Elementos urbanos.

\title{
INTRODUÇÃO
}

As áreas verdes urbanas exercem significativa influência na qualidade de vida e bemestar da população, oferecendo inúmeros benefícios aos citadinos. É nesse sentido que diversos pesquisadores têm realizado estudos referentes às áreas verdes urbanas, principalmente no tocante à manutenção e sobre o potencial em realçar a qualidade de vida e as funções ambientais, sociais e estéticas que contribuem para amenizar a gama de propriedades negativas da urbanização.

Dentre os estudos realizados com ênfase nos benefícios da vegetação urbana, destacamos as pesquisas realizadas por Amorim (2001), Nucci (2001), Bovo (2009) e Souza e Amorim (2016). Essas pesquisas apresentaram a importância da vegetação para o clima urbano, o controle da poluição do ar e da acústica, a melhoria da qualidade estética, os 
efeitos sobre a saúde mental e física da população, o aumento do conforto ambiental, a valorização econômica das propriedades e a formação de uma memória e de um patrimônio cultural.

A arborização viária, objeto desta pesquisa, faz parte da vegetação urbana e compreende todos os "[...] elementos vegetais de porte arbóreo, situados dentro dos limites urbanos que acompanham o trajeto das ruas e avenidas, e estão plantados nas calçadas, canteiros centrais, até mesmo em parques e praças" (SANTOS, 2019, p. 3).

Assim como as demais áreas verdes urbanas, a arborização viária das cidades proporciona diversos fatores positivos para a vida do cidadão, dentre eles destacamos: o bem estar psicológico; o efeito estético; sombreamento para pedestres e veículos; proteção e direcionamento do vento; amenização da poluição sonora; redução do impacto gerado pela água da chuva e de seu escorrimento superficial; auxílio na diminuição da temperatura, absorvendo os raios solares; preservação da fauna silvestre que ocupa a área urbana e a valorização econômica de imóveis (PIVETTA; SILVA FILHO, 2002)

Entretanto, dependendo da forma como ocorre o manejo dessa vegetação e da escolha das espécies plantadas, a vegetação urbana pode oferecer riscos à população e causar transtornos de ordens e magnitudes diversas. Nesse cenário, enquadram-se as árvores que compõem a arborização viária, as quais, ao mesmo tempo em que proporcionam conforto térmico e sombreamento e outros benefícios, também podem produzir alguns incômodos à população, quando a espécie plantada gera conflitos com outros equipamentos e elementos da infraestrutura urbana (ALBERTIN et al., 2011).

Para que a vegetação urbana, neste caso específico a arborização viária, tenha o impacto positivo na vida da população, pesquisas sobre o tema são necessárias. Para tanto, devemos analisar parâmetros objetivos, tais como os conflitos com outros elementos urbanos e a distribuição espacial na cidade, questões essas que se tornam mais claras se representadas cartograficamente. Questões subjetivas também devem ser consideradas na pesquisa, a exemplo citamos a percepção e opinião da população acerca do tema, sua satisfação com a situação e os problemas que vivencia no cotidiano.

Diante do exposto, a pesquisa objetiva caracterizar e analisar a arborização viária no centro da cidade de Campo Mourão/PR, evidenciando a percepção dos moradores. Esperase, sobretudo, que a pesquisa fomente novos olhares para a problemática da arborização urbana, inclusive em outros espaços do município, possibilitando que todos os benefícios possíveis de serem gerados pelas árvores urbanas cheguem a todos os habitantes podendo, assim, melhorar sua qualidade de vida. 


\section{ARBORIZAÇÃO VIÁRIA URBANA: APONTAMENTOS PARA UM DEBATE}

No Brasil, a arborização urbana é tutelada juridicamente de forma direta ou indireta com base na Política Nacional do Meio Ambiente (BRASIL, 1981), na Constituição Federal (BRASIL, 1988), na Lei dos Crimes Ambientais (BRASIL, 1998), no Estatuto da Cidade (BRASIL, 2001), além de outras legislações afins que trazem, de alguma forma, artigos que têm como foco salvaguardar o meio ambiente e garantir a qualidade de vida da população. No âmbito federal, a normatização é realizada de forma genérica e cabe aos municípios o papel da gestão ambiental urbana e da criação e implantação das regras locais relacionadas à vegetação urbana.

O conceito de arborização urbana é amplo e traz desdobramentos Miller; Haurer; Werner (1997, p. 32) a define como "[...] o conjunto de toda a vegetação arbórea e suas associações dentro e ao redor das cidades, desde pequenos núcleos urbanos até as grandes regiões metropolitanas". Assim, inclui as árvores das praças, parques, unidades de conservação, remanescentes de ecossistemas naturais ou plantadas e as árvores das ruas e avenidas. Estudos da área tratam especialmente da análise dos benefícios da vegetação.

Com relação aos efeitos da arborização sobre o microclima de determinado local, Gomes; Amorim (2003) comparou três praças do município de Presidente Prudente (SP) e constatou que de fato a que possuía maior incidência de árvores era também a que apresentava melhor conforto térmico. Por mais que o estudo tenha sido realizado em praças e não em vias, entendemos que o adequado planejamento de arborização nas vias pode gerar o mesmo impacto positivo no microclima e no bem-estar da população, com a ressalva de que precisam ser plantadas espécies adequadas também às particularidades das vias.

Em sua dissertação, Hernandez (2020) apresenta estudos de várias partes do mundo que comprovaram a eficácia da arborização urbana. $O$ estudo indica a melhora do microclima de uma localidade nos E.U.A., a diminuição de $3^{\circ}$ a $4^{\circ} \mathrm{C}$ da temperatura do ar dos lugares mais arborizados na Argentina e o plantio de árvores na Turquia que minimizaram a poluição sonora, além da amenização do stress verificada em outro estudo de Londres. Entretanto,

Apesar de todos esses benefícios, o planejamento da arborização urbana tem sido negligenciado dentro do planejamento urbano de algumas cidades brasileiras, causando uma série de problemas, tais como o uso de espécies inadequadas ao ambiente construído, que devido ao seu crescimento natural provocam deterioração da estrutura de calçadas, ruas e casas, e causam conflitos com as redes elétricas, sinalização, iluminação e demais equipamentos urbanos. Além disso, há o uso excessivo de algumas espécies, o que diminui a diversidade florística do patrimônio arbóreo da cidade (FRANÇA, SANTOS, GOMES, 2012, p.6). 
Em perspectiva semelhante, Rivelini e Gomes (2017, p. 90) apontam que "Apesar de sua importância, a cobertura vegetal é negligenciada na maior parte das cidades brasileiras, que são marcadas pela carência de áreas verdes, da arborização urbana, das praças e parques, principalmente nas áreas centrais do espaço urbano".

A falta de uma arborização adequada, em muitas cidades do Brasil, não ocorre apenas pelo desinteresse do poder público, mas também pelas poucas informações que conscientizem a população e os governantes a auxiliarem na gestão, no planejamento e na implantação da arborização urbana. Portanto, pesquisas sobre a temática apresentam-se de fundamental importância para balizar ações do poder público e fomentar propostas de intervenção. Também sobre as pesquisas da área, Hernandez (2020) assinala que a maioria foca as árvores e suas características, enquanto que a relação dos habitantes com essa temática ainda é um assunto pouco debatido, consistindo em uma lacuna no meio acadêmico.

De acordo com Schuch (2006), existem cidades no Brasil que possuem estudos que contribuíram para o levantamento de áreas verdes e arborização urbana, porém a maioria desses é feita por amostragens, sendo que os mesmos focam apenas o tema pesquisado, não desbravando a realidade do município. E ao compreendermos o meio urbano como espaço dinâmico, no qual várias transformações ocorrem constantemente e simultaneamente, não existem trabalhos que conseguiram abranger toda essa dinâmica atrelada à melhor intervenção possível no que diz respeito ao planejamento da arborização urbana.

Com relação aos levantamentos diagnósticos e aos inventários sobre a arborização viária e as condições das árvores, o processo de mapeamento é de suma importância, pois ajuda na compreensão de sua distribuição pelo espaço urbano, bem como na identificação de padrões de problemas e de uso de espécies inadequadas, entre outras questões. Santos (2019) salienta que, atualmente, esse processo é facilitado com o uso das geotecnologias empregadas no georreferenciamento de elementos do espaço geográfico.

Com esse avanço, um trabalho de levantamento arbóreo de determinada área, assim como de suas características, passou a ser mais viável, com menor demanda de tempo e maior exatidão dos dados coletados, do que há duas ou três décadas atrás, quando o acesso a imagens de satélite era privilégio de poucas instituições. Inúmeras tecnologias englobadas pelo geoprocessamento possibilitam que esses estudos possam ser cada vez mais abrangentes, especialmente os Sistemas de Informação Geográfica (SIGs), que permitem o processamento digital de imagens e permitem a sobreposição com outros dados, como aqueles coletados por receptor GPS (Global Position System) (SCHUCH, 2006). 
Junto a um inventário das condições da arborização urbana, os SIG's possibilitam a criação de um mapa em que as informações podem ser cruzadas entre elas, auxiliando um planejamento mais rápido e eficiente da arborização, afinal é imprescindível conhecer de fato a arborização para tomar decisões sobre a mesma (SANTOS, 2019), sendo possível criar mapas fiéis não apenas da localização das árvores, mas também de todo o conjunto de elementos urbanos ao seu redor.

Em estudo realizado no município do Rio de Janeiro por Pereira et al. (2019), a importância dos SIG's é apresentada pelo fato de que para o correto planejamento arbóreo de determinada região é imprescindível a organização de um grande volume de informações em um sistema computadorizado que possibilite a espacialização, análise e utilização nas melhores tomadas de decisões com relação às ações que serão destinadas à arborização viária. No estudo de caso os pesquisadores puderam levantar, sistematizar e comparar variáveis diversas através do georreferenciamento de 5412 indivíduos arbóreos.

Assim sendo, é possível que os responsáveis pela gestão pública municipal fomentem e realizem em seus municípios estudos de maior abrangência com relação à arborização viária e sua relação com outros elementos do meio urbano. A partir da sistematização das informações coletadas podem direcionar da melhor forma os recursos para o manejo adequado da arborização urbana, conforme afirma Tadenuma (2019).

Embora a população de uma cidade seja diretamente afetada pela qualidade da arborização viária, nem sempre os munícipes são consultados e escutados a respeito do assunto. A população precisa entender seu papel, não apenas no que diz respeito à fiscalização do poder público e suas responsabilidades, mas também de se colocar como parte integrante na atuação da transformação de cidade. Estudos que buscam compreender a percepção da população na arborização urbana são relevantes, pois mostram que, na maioria das vezes, a partir da atuação conjunta entre poder público e população é que se consegue o sucesso de um plano de arborização (ALMEIDA, FERNANDES, SOUTO, 2019).

Além disso, todo o meio urbano é uma representação sociocultural de sua população, seja pela sua participação efetiva ou de sua exclusão do processo de transformação do espaço em que vive. Assim sendo, Bonametti (2019, p. 54) escreve que "[...] o verde urbano reflete um alto grau cultural da sociedade quando esta entende que a vegetação, assim como o solo, o ar e a água, é uma necessidade do cenário urbano", e é nessa direção que os usos de tecnologias podem contribuir para a gestão e planejamento das áreas verdes urbanas, principalmente da arborização viária de forma mais eficaz.

Existem várias formas de inserir a população no processo de planejamento da arborização, como aplicação de questionários presenciais ou virtuais, disseminação desse 
debate em associações de bairros, conscientização pedagógica e outras. Para isso, é necessário que a mesma entenda a arborização urbana como parte de seu patrimônio público comunitário e participe dos processos decisórios com maior frequência e poder de voz.

\section{MATERIAIS E MÉTODOS}

O desenvolvimento da presente pesquisa pautou-se no método quali-quantitativo, a partir da análise de parâmetros objetivos e subjetivos relacionados à arborização viária urbana. Utilizamos como recorte espacial parte da área central da cidade de Campo Mourão, delimitada a partir das três principais avenidas (Figura 1), a saber: Avenida Manoel Mendes de Camargo, Avenida Capitão Índio Bandeira e Avenida Irmãos Pereira, no trecho entre as ruas São José e São Josafat, as quais juntas somam 33 quadras.

A organização dos procedimentos de pesquisa foi estruturada a partir de dois momentos. A primeira etapa pautou-se em atividades e critérios objetivos e consistiu no levantamento e mapeamento dos indivíduos arbóreos e dos conflitos ou não deles na área delimitada do centro do município de Campo Mourão. A segunda etapa foi subjetiva, na qual a população, a partir da disponibilização de um formulário virtual, pôde opinar sobre a arborização viária do município.

O processo de mapeamento foi realizado por meio de atividades programadas a campo, quando foram levantadas a quantidade de árvores e sua disposição neste espaço, assim como os possíveis conflitos com demais elementos da estrutura urbana. Com referência aos conflitos, foram previamente elencados e receberam uma sigla, que auxiliou no registro cartográfico desses durante o processo de mapeamento: Sem Conflito (SC), Conflito com a Fiação (CF), Forte Conflito com a Fiação (F-CF), Conflito com a Calçada (CC), Forte Conflito com a Calçada (F-CC), Conflito com Estacionamento (CE), Forte Conflito com Fiação e Conflito com Calçada (FCF-CC), Forte Conflito com Calçada e Conflito com Fiação (FCC-CF) e Forte Conflito com a Fiação e Forte Conflito com a Calçada (FCF-FCC).

O georreferenciamento dos indivíduos arbóreos foi realizado com o aplicativo Mapit GIS, através do sistema Androide de um celular Samsung J7. Os dados foram transportados primeiramente para a plataforma Google Earth Pro 7.3.3.7721 (64-bit), com imagens de Campo Mourão dos anos de 2015, 2017 e 2018, para posteriormente servirem de base para a formulação da representação cartográfica dos mesmos através do programa ArcGis 10.5.

O formulário semiestruturado virtual foi elaborado no Google Formulário com perguntas abertas e fechadas, disponibilizado em uma página de moradores da cidade na rede social Facebook. O formulário ficou disponível por 15 dias e foi acessado por 210 
pessoas e, desse quantitativo, 148 formulários foram respondidos corretamente (com dados completos) e aproveitados nesta pesquisa. As questões abarcavam tópicos sobre o perfil do participante, bem como sobre a percepção deles sobre a arborização viária, assim como as sugestões de melhoria para o cenário de Campo Mourão. Os resultados foram analisados e também sistematizados em gráficos.

Figura 1 - Localização da área pesquisada

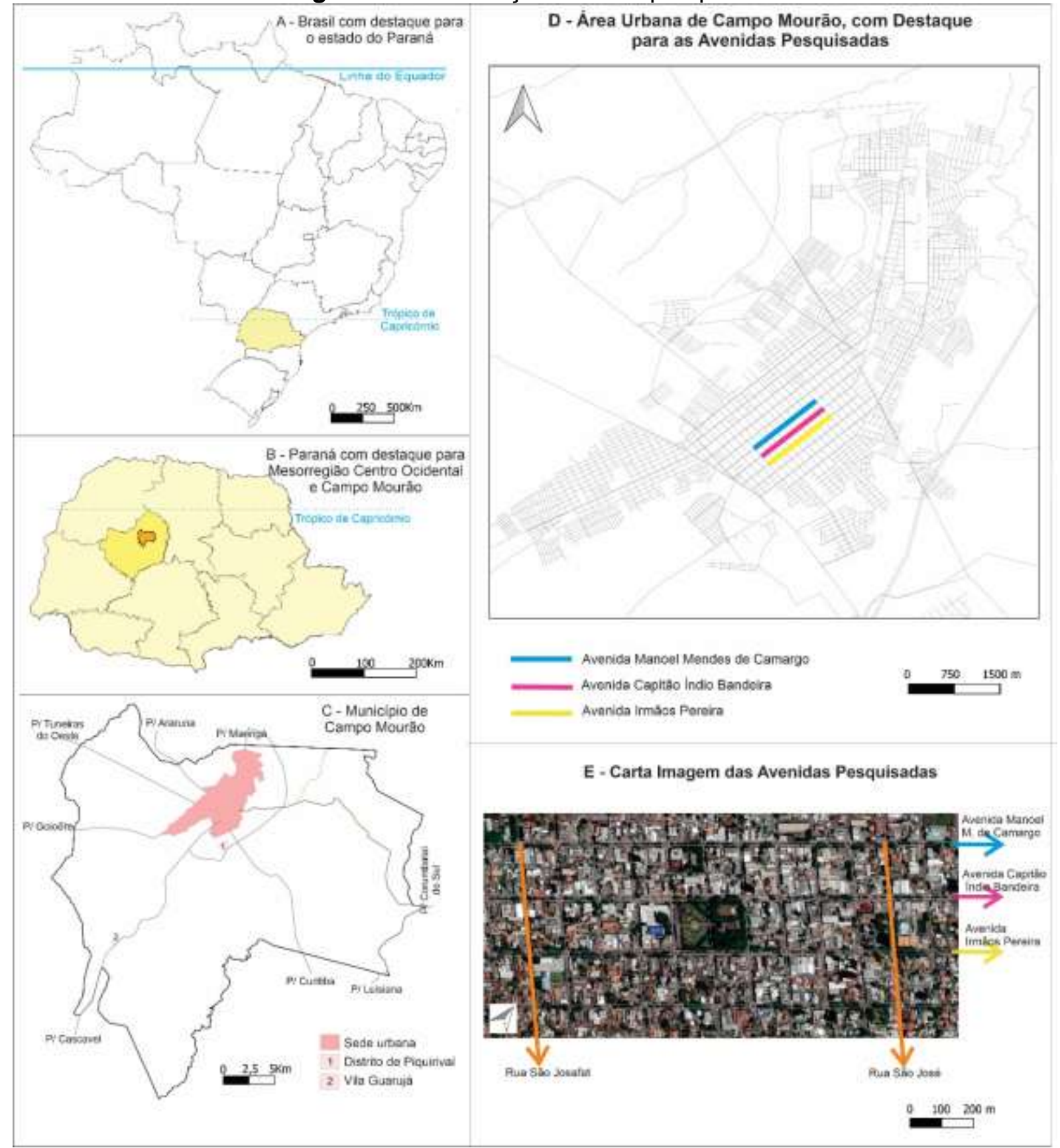

Fonte: IBGE (2015); OSMF (2021); Google (2020a). 


\section{ANÁLISE DO LEVANTAMENTO ARBÓREO DA VEGETAÇÃO VIÁRIA}

O levantamento arbóreo realizado resultou no cadastro de 571 árvores. Por mais que tenham sido encontradas diversas mudas, foram contabilizadas apenas aquelas que já estavam em uma fase mais avançada de desenvolvimento e que gerassem pelo menos sombra para os pedestres e vias.

Desse quantitativo, a Avenida Irmãos Pereira teve a maior incidência desses indivíduos, com 246 árvores. A segunda mais arborizada é a Avenida Manoel Mendes de Camargo com 172 árvores, enquanto que a menos arborizada é a Avenida Capitão Índio Bandeira com 153 árvores. As duas avenidas mais arborizadas possuem a fiação elétrica disposta pelo canteiro central enquanto a Avenida Capitão Índio Bandeira possui fiação elétrica sobre as calçadas.

Dessa forma, do total de 571 árvores distribuídas pelas avenidas em estudos 423 não apresentaram nenhum tipo de conflito com os elementos urbanos, totalizando $74 \%$ e apenas 26\% (148 indivíduos) apresentam conflitos com a fiação elétrica ou de telefonia ou ainda no calcamento com raízes expostas (Figura 2).

Figura 2 - Situação dos indivíduos arbóreos no centro de Campo Mourão

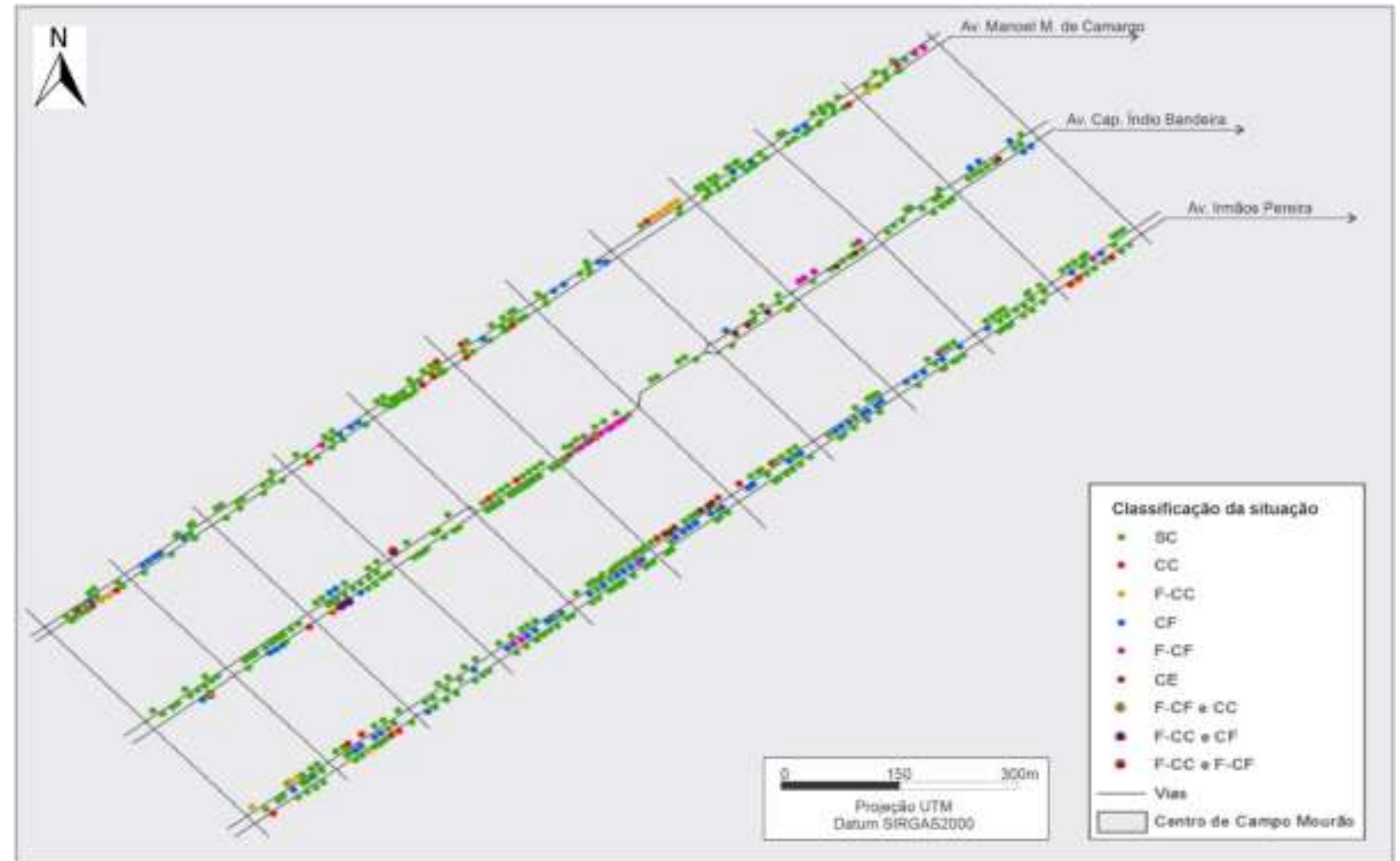

Fonte: Google (2020b). Elaboração: autores.

Os critérios para distinguir "Conflito com Fiação" de "Forte Conflito com Fiação" e "Conflito com Calçada" e "Forte Conflito com Calçada", basearam-se nas observações de 
campo. No caso dos conflitos com a fiação (elétrica ou de comunicação), observamos se o contato das árvores com os fios permitia ou não que eles seguissem em sua trajetória normal da fiação elétrica. Os dados levantados indicam que na Figura 3A existe um Forte Conflito, pois o fio não segue seu curso após encontrar com a árvore, diferente do segundo exemplo, em que o contato do fio se dá com galhos mais finos (Figura 3B).

Figura 3 - Exemplos dos conflitos das árvores com a fiação e a calçada

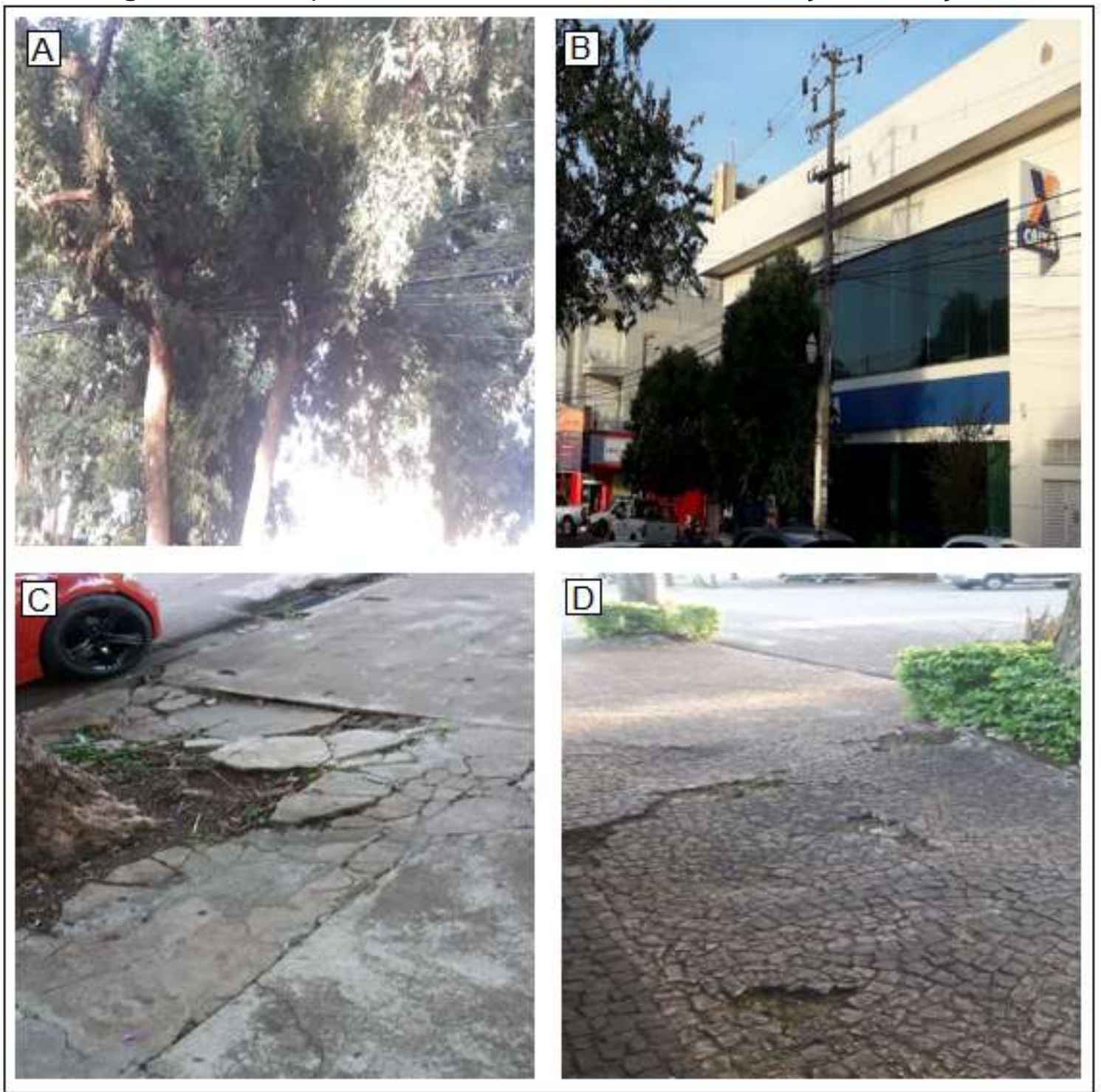

Fonte: autores (2020).

Quanto aos conflitos da arborização viária junto ao calçamento, podemos afirmar que estão associadas aos tipos de raízes, dimensão do sistema radicular, bem como às condições de estresse aos quais as plantas são submetidas. Esses conflitos ocorrem devido à distribuição, incompatibilidade do porte das árvores em relação à estrutura urbana, ocasionando, assim, danos às calçadas e também rompimento de tubulações da rede de abastecimento de água e esgoto ou de fiação elétricas subterrâneas. No caso da área de 
estudo, constatamos problemas de raízes expostas que dificultam o acesso a cadeirantes, ou seja, dificuldade a acessibilidade e a mobilidade das pessoas pelas calçadas (Figura 3C e 3D). De acordo com o levantamento realizado, não encontramos nenhum problema relacionado ao rompimento de tubulações ou de rede elétrica subterrânea.

Ao dividirmos cada uma das vias em 11 partes, a partir da delimitação da área de estudo, foram totalizadas 33 quadras. Na sequência computamos o total de árvores e dividimos pelos números de quadras, totalizando uma média de 17 árvores por quadra.

Porém, percebemos que apenas a Avenida Irmãos Pereira não tem nenhuma quadra com menos de 15 árvores, enquanto que a Avenida Capitão Índio Bandeira (ao centro) apresenta sete quadras com menos de 15 indivíduos arbóreos, e a Avenida Manoel Mendes de Camargo (ao norte) tem seis quadras com essa mesma característica. Portanto, o equivalente a $39 \%$ das partes das avenidas possui uma arborização inferior à média, apontando para uma distribuição desigual dos indivíduos arbóreos pelas avenidas.

Das 146 árvores que apresentam algum conflito (Figura 4), cinco possuem mais de um conflito simultaneamente e estão localizadas na primeira, terceira, quarta e sexta quadra da Avenida Capitão Índio Bandeira. São os casos representados por FCF-CC, encontrados em duas árvores, FCC-CF em outras duas e FCF-FCC em uma, todos esses duplos conflitos foram constatados na Avenida Capitão Índio Bandeira que está entre as outras duas. Apenas essa avenida possibilita esse tipo de conflito por ser a única com a fiação nas calçadas.

Quanto aos diferentes tipos de conflitos elencados nesta pesquisa, a Avenida Capitão Índio Bandeira é a que possui a menor porcentagem de conflitos entre as árvores nela dispostas (22\%). Porém, observa-se que $41 \%$ do total de conflitos são fortes, um deles é com a calçada e 13 com a fiação elétrica.

Porém, se comparamos a Avenida Irmão Pereira com a Avenida Capitão Índio Bandeira esta é a que apresenta maior porcentagem de Fortes Conflitos, seja com relação ao total de árvores que possui ou com o total de conflitos da via. Os apenas "Conflitos" foram quatro com a calçada, 13 com a fiação e cinco com estacionamento.

Das árvores da Avenida Irmãos Pereira, 30\% apresentaram algum tipo de conflito, sendo a maior porcentagem dentre as três. Porém, quando se trata de Fortes Conflitos, possui apenas $4 \%$ do total de árvores, e com relação àquelas que têm conflitos, seus $13 \%$ de Fortes Conflitos também é a menor porcentagem dentre as três. Esses Fortes Conflitos estão bem divididos, sendo cinco em calçadas e cinco em fiação. Já aqueles considerados como Conflitos foram identificados 12 com calçadas, 46 com fiação e seis com estacionamento.

E por fim, a Avenida Manoel Mendes de Camargo com 25\% de suas árvores apresentando algum tipo de conflito. Aqueles considerados Fortes representam $8 \%$ do total 
de árvores, enquanto que do total de conflitos foram $32 \%$. Os conflitos com a calçada são 11 e com a fiação 18, não existindo estacionamentos sobre o calçamento, caso que ocorre em uma das quadras da Avenida Irmãos Pereira e nem onde poderia ser o canteiro central, como ocorre nas últimas quatro quadras levantadas da Avenida Capitão Índio Bandeira.

Figura 4 - Árvores em conflito na área delimitada

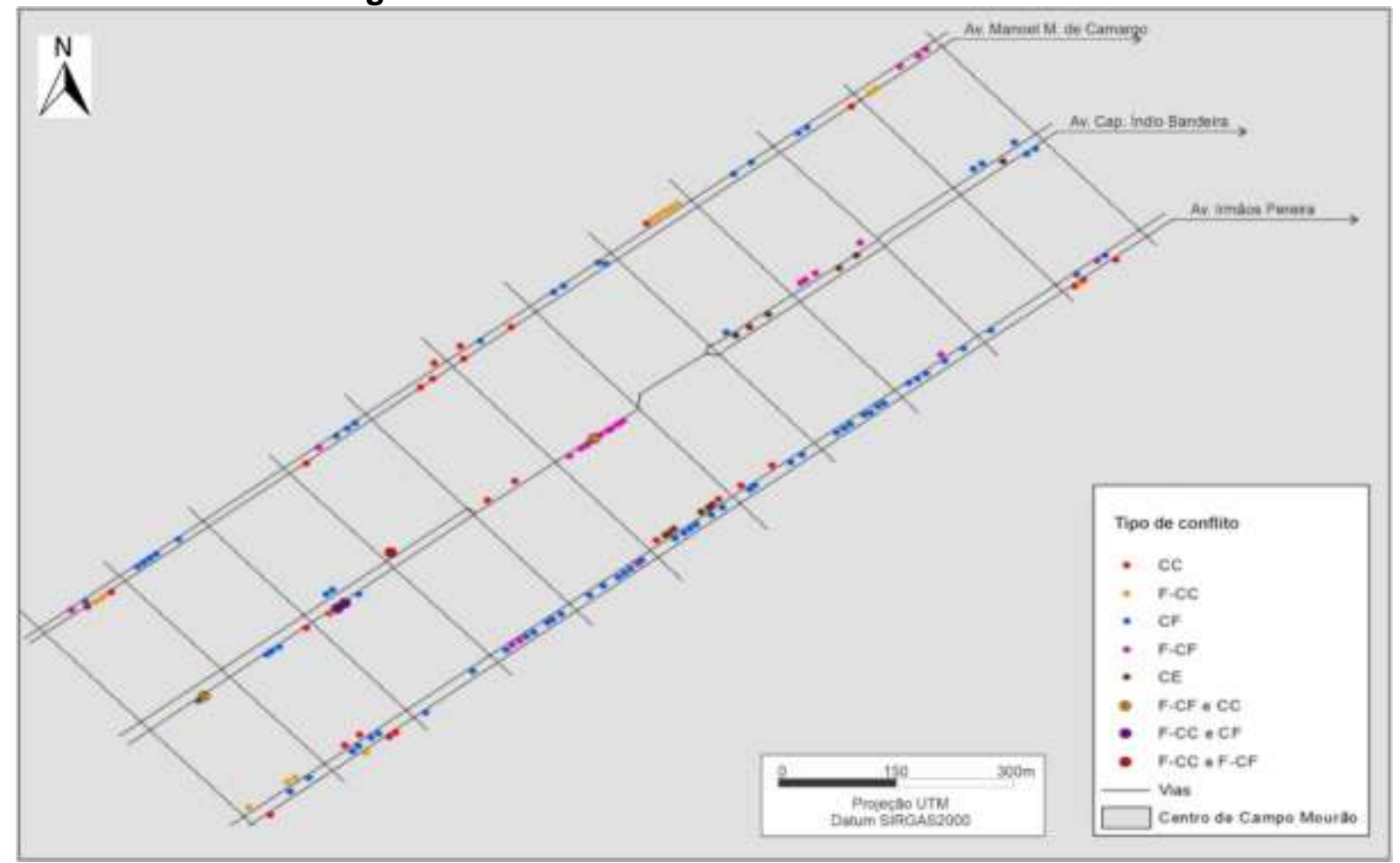

Fonte: Google (2020b). Elaboração: autores.

No geral dos conflitos causados pelos 146 indivíduos, 98 se dão com a fiação, 42 em calçadas e 11 nos estacionamentos, de modo que cinco árvores tiveram mais do que um conflito. Ainda que sejam alarmantes, dos $67 \%$ de conflitos com a fiação apenas $23 \%$ são Fortes. Porém, quando tratamos dos $28 \%$ que representam os conflitos com calçadas, $35 \%$ são Fortes e dificultam ou impossibilitam a passagem de alguns pedestres ou cadeirantes.

Para evitar esses conflitos, é necessário que os responsáveis pela manutenção, conservação e planejamento da arborização viária planejem todas as ações desde o plantio com espécies adequadas, reparos com as podas e plantio adequado de forma a evitar conflitos fortes.

\section{A PERCEPÇÃO DA POPULAÇÃo SOBRE A ARBORIZAÇÃO URBANA}

O Manual para Elaboração da Arborização Urbana do Estado do Paraná destaca a relevância do estudo da percepção da população referente à arborização urbana. Para 
tanto, propõe que o estudo da percepção da população seja uma ferramenta que visa "[...] garantir a participação da população na construção do Plano Municipal de Arborização Urbana, pois garante captar como a população vê e convive com as árvores urbanas de seu município" (PARANÁ, 2018, p.31). Para tanto, apresenta as seguintes funções:

a) Embasar os gestores públicos na construção de um Plano Municipal de Arborização Urbana que realmente atenda aos anseios da população e também otimizar as ações a serem desenvolvidas no Plano; b) Levantar as principais funções desempenhadas pelas Manual para Elaboração do Plano Municipal de Arborização Urbana segundo a população; c) Delimitar os principais desafios que possam entravar o desenvolvimento de ações do Plano, trabalhá-los junto à população e saná-los de forma participativa; d) Envolver e corresponsabilizar a população na preservação da arborização urbana viária, reduzindo o vandalismo; e) Reduzir as "resistências", aproximar a população na gestão do verde urbano e ampliar seu entendimento sobre o manejo das árvores; $\mathrm{f}$ ) Balizar as demandas de temas e metodologias a serem enfocados nas ações de Educação Ambiental; g) Auxiliar na obtenção de critérios e demandas de espécies que podem ser implantadas na arborização com a participação da população (PARANÁ, 2018, p. 31-32).

Dessa forma, buscamos por meio da percepção da população compreender alguns aspectos relacionados aos moradores da cidade de Campo Mourão, pois esses diagnósticos contam com a vivência dos moradores, indicando tanto os aspectos positivos quanto os negativos da arborização urbana.

Assim, a segunda etapa da pesquisa teve por objetivo analisar a percepção da população sobre a arborização viária da área pesquisada, para tanto foi disponibilizado para a população um questionário organizado em duas partes. Na primeira parte, buscamos identificar o perfil dos moradores que responderam o questionário, já na segunda parte as questões foram relacionadas à arborização viária. É importante salientar que a compreensão do perfil das pessoas que responderam o questionário é fundamental, pois expressam o grau de interesse e o compromisso dos mesmos com o ambiente urbano; outro ponto que consideramos foi o grau de escolaridade que interferiram nas respostas, bem como as faixas etárias por apresentarem diferentes pontos de vista sobre a arborização.

Dos 148 habitantes do município que se propuseram a responder os formulários online, $81 \%$ são mulheres e 19\% são homens. Com predominância da faixa etária entre 21 a 40 anos (62\%); dos que estão entre 41 a 60 anos foram representadas por $32 \%$ dos entrevistados; $4 \%$ de 18 a 20 anos e maiores que 60 anos $2 \%$, dentre eles, 120 moram há mais de 10 anos na cidade. $E$ os que moram no centro são $35,4 \%$; enquanto $6,2 \%$ representam os moradores do Jd. Aeroporto e o mesmo para o Jd. Izabel; 4,2\% moram no Jd. Flora e os demais (48\%) em outros bairros.

Da escolaridade informada, a maioria (42\%) tem pós-graduação; seguida por aqueles com graduação incompleta (31\%). Os que concluíram a graduação $(21 \%)$ demonstraram 
mais importância da participação em pesquisas que visem a melhoria dessa questão no município do que aqueles com o ensino médio completo (4\%) ou incompleto (2\%). As principais atividades profissionais informadas foram: contratado (29\%), funcionário público (25\%), profissional liberal e desempregado com $5 \%$ cada, aposentados e professores correspondem a $6,3 \%$ cada, autônoma $4 \%$ e outras $8 \%$.

Após o levantamento dos perfis dos moradores de Campo Mourão que responderam o questionário, buscamos entender qual a compreensão e opinião deles sobre a arborização viária. A síntese dos dados coletados encontra-se representada nos gráficos da Figura 5.

Figura 5 - Conhecimento do termo 'arborização viária' e percepção dos entrevistados

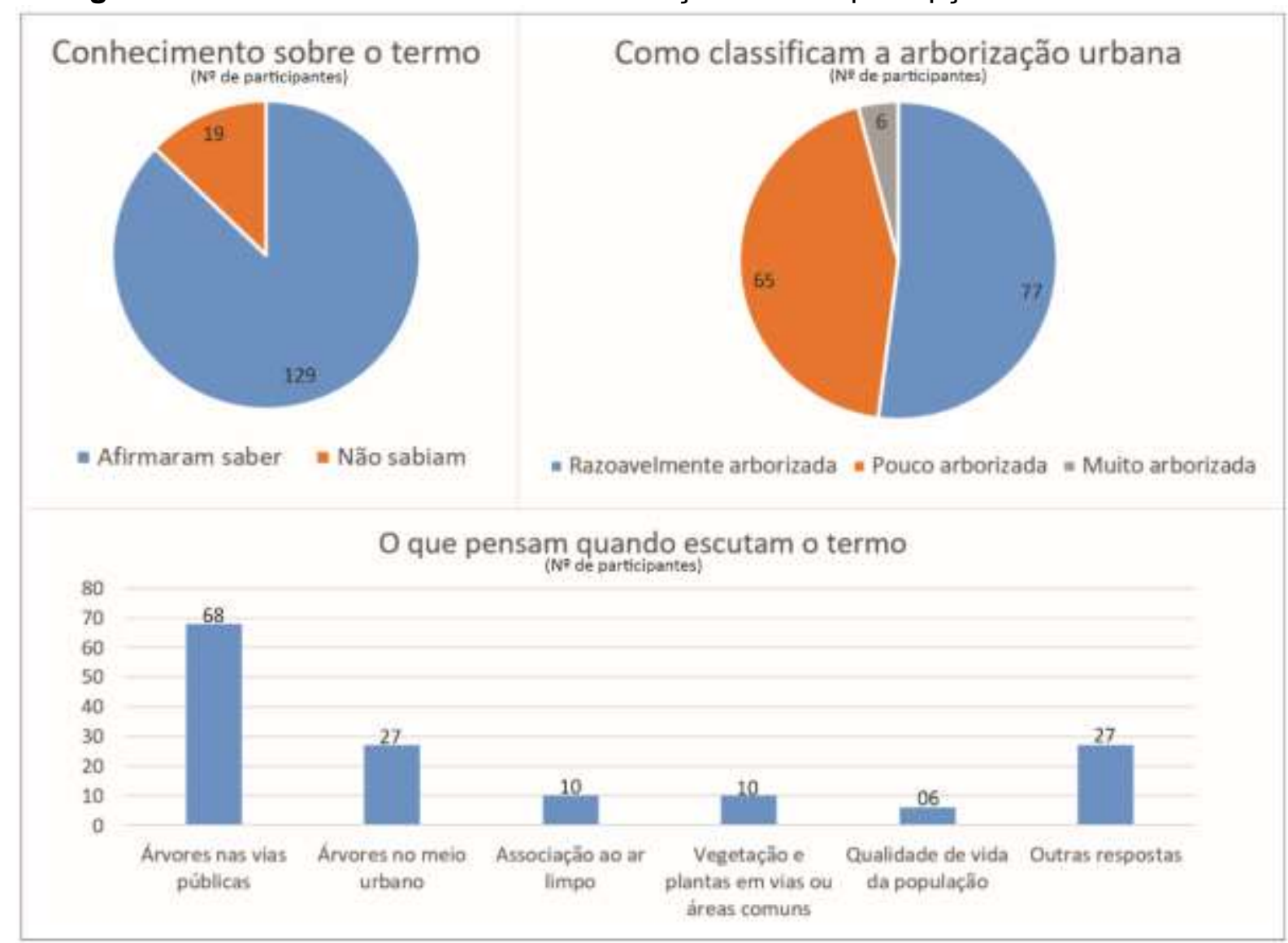

Fonte: autores (2020).

Quando questionados se sabiam o que significava o termo "arborização viária", 87\% afirmaram saber, enquanto que $13 \%$ disseram que não, porém pedimos que dissessem com suas palavras qual a primeira coisa que eles pensam quando escutam esse termo. Das 148 respostas, $46 \%$ responderam corretamente o significado, relacionando as árvores com as vias públicas, enquanto que $18 \%$ citaram árvores no meio urbano, sem nenhum tipo de especificação de qual lugar da cidade. Dez pessoas (7\%) pensaram em ar limpo, mesma quantidade que pensou em vegetação ou plantas em vias ou áreas comuns, enquanto $4 \%$ citaram qualidade de vida da população. As outras respostas somaram $18 \%$. 
Na sequência foi feito o seguinte questionamento: na sua opinião, quem é responsável pela arborização viária? De acordo com o questionário, a maioria respondeu que o responsável pela arborização viária é o poder público municipal (83\%), enquanto que $12 \%$ atribui a responsabilidade à população e 4\% disseram que são todos, ou seja, os funcionários públicos municipais responsáveis pela arborização urbana e a população; também a companhia elétrica aparece na opinião de alguns.

Antes de perguntarmos sobre como o entrevistado classificaria a arborização viária do município foi explicado o significado do termo. Com isso, apenas $4 \%$ acreditam viver em uma cidade muito arborizada; já a maioria (52\%) acham as vias razoavelmente arborizadas enquanto os demais $44 \%$ acham que é pouco arborizada (Figura 5).

Por meio de questão de múltipla escolha os moradores puderam expressar a sua opinião a respeito das vantagens que a arborização urbana proporciona para a população. Dentre as vantagens consideradas mais relevantes (Figura 6), estão a preservação da biodiversidade com $38 \%$; seguido (25\%) de oferecer sombra; redução da temperatura com 19\%; redução da poluição com $14 \%$ e, por fim, a redução do impacto da chuva corresponde a $4 \%$ das respostas.

Figura 6 - Principais vantagens e desvantagens da arborização viária

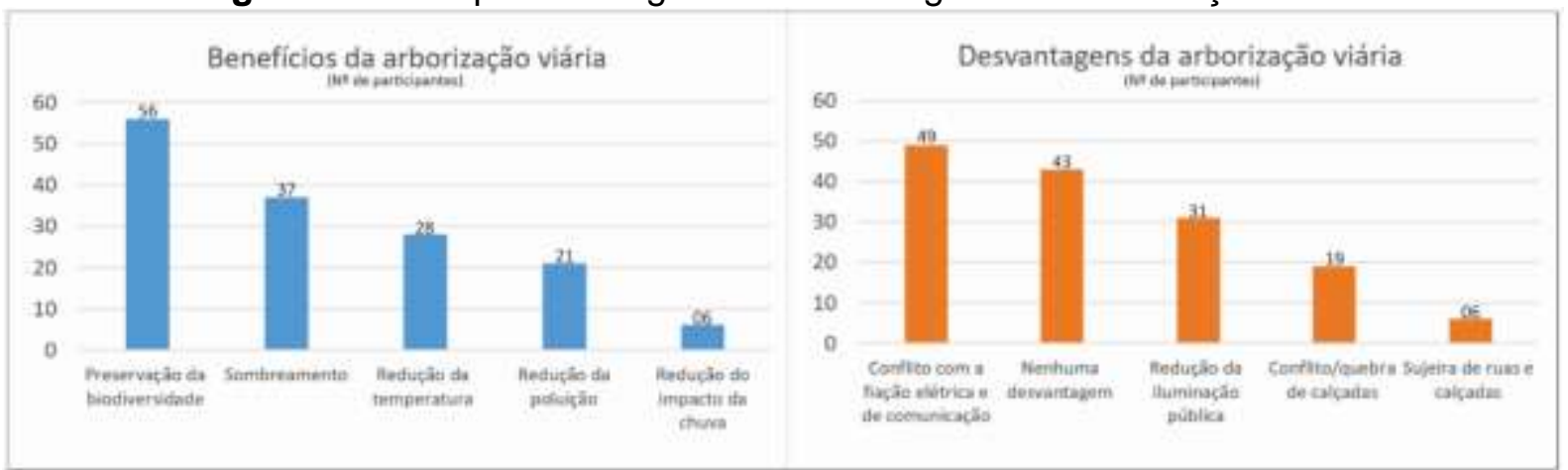

Fonte: autores (2020).

Ao serem questionados em pergunta aberta se tinham mais alguma ideia sobre as vantagens proporcionadas pela arborização, do total de 148 que responderam o questionário, 80 indicaram outros elementos como: o embelezamento da cidade; a contribuição para o bem-estar psicológico da população; a contribuição com a melhoria do ar; o auxílio com relação à diminuição da poluição sonora; a produção de frutos e abrigo aos pássaros, o bem-estar psicológico que elas proporcionam foi citado por 18 deles; os demais não indicaram nenhuma informação adicional.

Em seguida, por meio de questão de múltipla escolha foi possível indicar as desvantagens da arborização viária, e para tanto puderam assinalar mais de uma opção. De acordo com os dados levantados nos questionários, verificamos que $33 \%$ indicaram 0 
conflito com a fiação elétrica e de comunicação, $29 \%$ não veem nenhuma desvantagem da arborização urbana, seguido da redução da iluminação pública em $21 \%$. E por fim, em menor percentual, aparecem o conflito/quebra de calçadas com $13 \%$ e sujeira de ruas e calçadas aparecem com 4\% (Figura 6).

Nessa questão aparecem outras desvantagens que foram pontuadas pelos moradores, como, por exemplo, que as árvores atrapalham o trânsito por falta de poda por parte dos funcionários municipais que são responsáveis por este setor ou ainda podas malfeitas por parte da população e também pela companhia elétrica e de telefonia. Outro ponto destacado se refere à população que não segue as normas de plantio, e também a ausência de planejamento voltado para a conservação e manutenção da arborização por parte dos responsáveis pela gestão e planejamento, o que ocasiona quedas de árvores com certa frequência.

Somando as desvantagens, aparecem também a poda e as quedas de árvores que são assinaladas como problemas, uma vez que a gestão pública municipal demora para autorizar o serviço ou remover às árvores que estão com fitossanidade, árvores de riscos ou espécies invasoras. É importante destacar que $43 \%$ das observações acerca das desvantagens da arborização viária estão intimamente ligadas ao poder público municipal.

O setor público responsável pela arborização urbana e a população devem ficar atentos a outros tipos de desvantagens da arborização urbana como, por exemplo: a inserção de espécies exóticas invasoras; árvores com características não adequadas ao local (tóxicas, alergênicas, com espinhos, com frutos grandes); fitossanidade (pragas e doenças) - para toda a árvore que apresentar pragas como cupim, brocas e fungos é necessário que se faça a análise de risco de queda; árvores senescentes ou de risco; arborização composta por uma única espécie; tipos de defeitos estruturais presentes, sinais e tipos de podas realizadas, principalmente a poda drástica, a poda unilateral e a de elevação excessiva (CONFEA, 2018; ABNT, 2020). Ao verificar esses problemas o poder público municipal deve dar prioridade por meio de um planejamento e manejo da arborização viária.

Quando questionados sobre sua atitude diante de um ato de depredação de uma árvore em sua rua, obtivemos as seguintes respostas: 54\% denunciariam; 14\% iriam conversar; $19 \%$ chamariam a atenção; $12 \%$ não sabiam o que faria.

Já sobre o tipo vegetação que escolheria para arborizar as cidades, as respostas foram: árvores de qualquer espécie (79\%); escolheria o tipo de árvore (10\%); arbustos (2\%) e não souberam corresponde a $8 \%$. Complementando essa resposta, os moradores que responderam o questionário puderam opinar sobre quais tipos de árvores gostariam que compusessem a arborização viária, e é importante salientar que não houve nenhum tipo de 
interferência por parte dos pesquisadores. As árvores citadas foram os ipês que apareceram em 31 questionários, seguido de frutífera (28), oiti (16), quaresmeira, flamboyant e manacáda-serra que foram citadas nove vezes cada, sibipiruna seis vezes, enquanto outras espécies arbóreas e arbustivas 40 vezes.

Das árvores que foram sugeridas por mais de um entrevistado, com exceção das frutíferas, que podem ser inúmeras, a flamboyant é a única que não é originária do Brasil, vinda da África e é encontrada em diversas cidades do Brasil.

Segundo o Manual Técnico de Arborização Urbana da Prefeitura de São Paulo (SÃO PAULO, 2015), as espécies indicadas para serem plantadas em calçadas e que são consagradas nas ruas da cidade, citadas pelos entrevistados são o ipê, podendo ser o ipêrosa-anão (3-5 metros), ipê-amarelo (4-10 metros) e ipê branco (7-12 metros), assim como o oiti (8-15 metros) e a quaresmeira (8-12 metros). É importante destacar que nem todos os elementos contidos no Manual Técnico de Arborização Urbana da Prefeitura de São Paulo podem ser aplicados na cidade de Campo Mourão, porém no que tange aos exemplos de vegetação citados, é possível que possam ser desenvolvidos sem ocasionar nenhum problema para o ambiente local.

As espécies indicadas no manual podem atingir até 15 metros de altura e, nesse caso, haverá comprometimento da fiação elétrica. Para resolver esse problema, é necessário que haja a constante manutenção da vegetação urbana por meio de podas corretas, impedindo, assim, que as vegetações atinjam a rede elétrica.

Porém, por mais que sejam plantadas apenas espécies indicadas pelo poder público, é imprescindível observar as espécies indicadas pelo Manual, e apenas o ipê-rosa-anão não chega a atingir mais de 6 metros de altura, que é justamente a altura mínima de fios da rede elétrica, de maneira que as podas corretas devem ser realizadas para que as árvores venham a crescer sem entrar em conflito com a rede elétrica.

Em mais uma questão aberta, perguntados sobre a opinião dos entrevistados a respeito da arborização viária de Campo Mourão, muitos dos problemas citados foram reafirmados, contudo uma observação pertinente que ainda não havia aparecido para a pesquisa e que foi citada por 15 dos 148 moradores que responderam ao questionário foi a evidente diferença entre a arborização viária central com relação à periférica do município, apelando para que o poder público municipal passe a se preocupar com um planejamento que não vise apenas a área central, mas todos os bairros do município, principalmente os mais novos.

Apenas três dos entrevistados não estavam dispostos a contribuir com respostas sobre a arborização viária, enquanto que entre os demais ideias como ajudar a plantar, cuidar e fiscalizar as árvores do município foram as mais recorrentes, além de outras como de maior participação da população na política destinada ao assunto, que fossem realizadas 
ações de conscientização da população por parte dos gestores municipais e a criação de programas ambientais em parcerias com colégios e associações de bairro. Além disso, em suas últimas respostas, $82 \%$ afirmaram estarem dispostos a receber uma muda de árvore para plantar e cuidar em frente de suas residências.

\section{CONSIDERAÇÕES FINAIS}

A arborização urbana contribui para a melhor qualidade de vida, valoriza a estética das ruas e avenidas, além de conservar a biodiversidade no meio urbano. Consideramos que a arborização sofre os efeitos da urbanização, da gestão municipal e da sociedade. Para resolver esses problemas, o planejamento da arborização viária é essencial, evitando, assim, conflitos no meio urbano.

Os benefícios da arborização viária, sejam visíveis ou não, conseguem trazer melhorias significativas para a qualidade de vida da população. Quando sentimos bem-estar físico e psicológico, muitas vezes não pensamos em todos os fatores envolvidos, e um desses fatores é a arborização viária, que proporciona ao cidadão tipos de sensações, tendo em vista que o contato com os elementos naturais, além de fazer bem para a saúde, proporciona uma estética agradável, uma harmonia entre o mundo do concreto e da natureza nas cidades.

A área estudada apresentou uma média razoável de 17 indivíduos arbóreos por quadra, contudo não estão bem distribuídos. E por mais que o número de Fortes Conflitos que as árvores apresentam ocorre em apenas $6 \%$ do total de árvores, é imprescindível que ações do poder público busquem sempre diminuir esse número devido aos sérios danos que podem ser causados por eles.

A adesão relacionada ao quantitativo de respostas do questionário obtidas via acesso à página da web referente à arborização foram satisfatórias. Porém, essa adesão poderia ser maior se a população do município tivesse a compreensão sobre a relevância da arborização viária no que tange aos benefícios. Outro ponto a ser destacado refere-se à ausência do poder público na conservação e manutenção por meio de um planejamento sistematizado envolvendo os aspectos socioambientais que necessitam ser melhorados. É importante salientar que o formulário ficou disponível por 15 dias, mas aqueles que participaram, na maioria, foram mulheres com escolaridade superior ao ensino médio, e demonstraram interesse pela melhoria da arborização no município, inclusive com exemplos e opiniões relevantes de como o poder público deveria melhorar esse tema no município.

O uso de geotecnologias para obtenção dos resultados contribuiu para o levantamento da situação dos indivíduos arbóreos no centro de Campo Mourão e também para identificar 
a árvores em situação de conflito na área delimitada. Assim, consideramos que os usos de tais ferramentas auxiliam no levantamento de dados e mapeamento visando agilizar o processo de melhoria do espaço público urbano no que tange à arborização urbana.

Portanto, consideramos que a arborização viária contribui com vários benefícios, dentre eles podemos destacar: estabilidade climática, conforto ambiental, qualidade do ar, redução da poluição, saúde física e mental da população, além de auxiliar na conservação do ambiente ecologicamente equilibrado. Porém, a arborização pode gerar vários problemas para os gestores municipais quando não planejada de forma adequada, envolvendo principalmente prejuízos na rede elétrica, rede de água e esgoto e obstáculos nas vias de circulação de pedestres.

É importante destacar que o uso de novas tecnologias aplicadas ao planejamento da arborização viária contribui para a gestão, planejamento e monitoramento, quando utilizadas pelos gestores municipais de forma adequada por meio de um banco de dados indicando todas as caraterísticas das espécies e sua distribuição pela malha urbana. A participação dos habitantes do município em parceria com o poder público municipal é fundamental para a harmonia entre as árvores e os elementos urbanos, podendo, assim, gerar ou maximizar o bem-estar de todos os habitantes.

\section{REFERÊNCIAS}

ABNT. Associação Brasileira de Normas Técnicas. NBR 9050: Acessibilidade a edificações, mobiliário, espaços e equipamentos urbanos. 2020. Disponível em:

<http://www.portaldeacessibilidade.rs.gov.br/uploads/1596842151Emenda_1_ABNT_NBR_9 050_em_03_de_agosto_de_2020.pdf>. Acesso em: 30 mar. 2021.

ALBERTIN, Ricardo Massulo et al. Diagnóstico Quali-quantitativo da arborização viária de Nova Esperança, Paraná, Brasil. Revista da Sociedade Brasileira de Arborização Urbana, Curitiba, v. 6, n. 3, p. 128-148, 2011. Disponível em:<https://revistas.ufpr.br/revsbau/article/view/66477>. Acesso em: 15 mar. 2021.

AMORIM, Margarete Cristiane de Costa Trindade. Caracterização das Áreas Verdes em Presidente Prudente. In: SPÓSITO, Maria Encarnação Beltrão. Textos e contextos para a leitura geográfica de uma cidade média. Presidente Prudente: Programa de PósGraduação em Geografia. FCT/UNESP GASPERR, 2001. p.32-45.

ALMEIDA, Ediglécia Pereira de; FERNANDES, Samara Paulo Santos; SOUTO, Patrícia Carneiro. Arborização urbana na percepção da população do distrito de lara no Ceará. Revista da Sociedade Brasileira de Arborização Urbana, Curitiba, v. 14, n. 2, p. 16-30, 2019. Disponível em: < https://revistas.ufpr.br/revsbau/article/view/65692/pdf>. Acesso em: 06 mar. 2021.

BONAMETTI, João Henrique. A Arborização Urbana. Terra \& Cultura, Londrina, Ano XIX, v. 36, p. 51-55, 2019. Disponível em: < https://web.unifil.br/docs/revista_eletronica/terra_cultura/36/Terra\%20e\%20Cultura_366.pdf $>$. Acesso em: 15 abr. 2021.

BOVO, Marcos Clair. Áreas verdes urbanas, imagem e uso: um estudo geográfico sobre a cidade de Maringá-PR. 2009. Tese (Doutorado em Geografia) - Universidade Estadual 
Paulista, Presidente Prudente, 2009. Disponível em $<$ https://repositorio.unesp.br/handle/11449/105006>. Acesso em: 30 abr. 2021.

BRASIL. Lei no 6.938, de 31 de agosto de 1981. Dispõe sobre a Política Nacional do Meio Ambiente, seus fins e mecanismos de formulação e aplicação, e dá outras providências. Disponível em: <http://www.planalto.gov.br/ccivil_03/LEIS/L6938.htm>. Acesso em: 10 jun. 2020.

BRASIL. Constituição da República Federativa do Brasil. Texto original, de 5 de outubro de 1988. Disponível em: <http://www2.camara.leg.br/legin/fed/consti/1988/constituicao-19885-outubro-1988-322142-publicacaooriginal-1-pl.html>. Acesso em: 10 jun. 2020.

BRASIL. Lei no 9.605, de 12 de fevereiro de 1998. Dispõe sobre as sanções penais e administrativas derivadas de condutas e atividades lesivas ao meio ambiente, e dá outras providências. Disponível em: <http://www.planalto.gov.br/ccivil_03/leis/L9605.htm>. Acesso em: 10 jun. 2020.

BRASIL. Estatuto da Cidade. Lei 10.257, de 10 de julho de 2001. Regulamenta os arts. 182 e 183 da Constituição Federal, estabelece diretrizes gerais da política urbana e dá outras providências. Disponível em:

<http://www.planalto.gov.br/ccivil_03/LEIS/LEIS_2001/L10257.htm>. Acesso em: 10 jun. 2020.

CONFEA. Conselho Federal de Engenharia e Agronomia. Acessibilidade - Guia prático para o projeto de adaptações e novas normas. Confea/Comissão Temática de

Acessibilidade e Equipamentos-CTAE, 2018. Disponível em:

<https://www.confea.org.br/sites/default/files/antigos/CartilhaAcessibilidade2018_site.pdf>. Acesso em: 01 mai. 2021.

FRANÇA, Tainã Potiguara França de; SANTOS, Carla Zoaid Alves dos; GOMES, Laura Jane. Arborização de Aracaju: uma percepção dos seus moradores. Geografia, Londrina, v. 21, n.2., p. 05-22, 2012.Disponível em: <

http://www.uel.br/revistas/uel/index.php/geografia/article/view/9507>. Acesso em: 30 abr. 2021.

GOOGLE. Google Satélite. Mosaico de Imagens de Satélite de Campo Mourão - Paraná. 2020a.

GOOGLE. Google Earth Pro. 2020b.

GOMES, Marcos Antônio Silvestre; AMORIM, Margarete Cristiane de Costa Trindade Arborização e conforto térmico no espaço urbano: estudo de caso nas praças públicas de Presidente Prudente (SP). Caminhos de Geografia, Uberlândia, v. 4, n. 10, p. 94-106, 2003. Disponível em: <

http://www.seer.ufu.br/index.php/caminhosdegeografia/article/view/15319>. Acesso em: 30 abr. 2021.

HERNANDEZ, Jessika Alesandra Zambrano. Mapeamento da arborização de calçadas nas vias públicas de Ponta Grossa - PR com uso de sensoriamento remoto. 2020. Dissertação (Mestrado em Gestão do Território) - Universidade Estadual de Ponta Grossa, Ponta Grossa 2020. Disponível em:<https://tede2.uepg.br/jspui/handle/prefix/3081 >. Acesso em: 29 abr. 2021.

IBGE. Instituto Brasileiro de Geografia e Estatística. Geociências. Organização do território. Malha municipal, 2015. Disponível em < https://www.ibge.gov.br/geociencias/organizacaodo-territorio/15774-malhas.html?=\&t=downloads >. Acesso em: 01 jun. 2020.

MILLER, Robert; HAURER, Richard; WERNER, Les. Urban Foresty: Planning and Managing Urban Greenspaces. Upper Saddle River: Prentice Hall, 1997. 
NUCCl, João Carlos. Qualidade ambiental e adensamento Urbano. São Paulo: Humanistas/FFLCH-USP, 2001.

OSMF. Fundação OpenStreetMap. Dados abertos. 2021. Disponível em:

https://www.openstreetmap.org/copyright?locale=pt-BR. Acesso em: 02 maio 2021.

PARANÁ. Manual para Elaboração do Plano Municipal de Arborização Urbana. Ministério Público do Estado do Paraná. Curitiba, 2018.

PEREIRA, Aloiso Wernek et al. Análise quali-quantitativa da arborização urbana de dois bairros do município do Rio de Janeiro por meio do geoprocessamento. Revista da

Sociedade Brasileira de Arborização Urbana, Curitiba, v. 14, n. 2, p. 43-61, 2019.

Disponível em: <https://revistas.ufpr.br/revsbau/article/view/65812>. Acesso em: 30 abr. 2021.

PIVETTA, Kathia Fernandes Lopes; SILVA FILHO, Demóstones Ferreira Silva.

Arborização urbana. Jaboticabal: UNESP/FCAV/FUNEP, 2002. p. 74.

RIVELINI, Poliana Montoro; GOMES, Márcio Fernando. Análise da arborização viária e sua relação com a infraestrutura urbana na Rua Luiz Pereira Barreto, Araçatuba-SP.

Contemporânea Revista UniToledo: Arquitetura, Comunicação, Design, Educação e História, Araçatuba, v. 2, n. 1, p. 88-103, 2017. Disponível em:

<http://ojs.toledo.br/index.php/contemporanea/article/view/2553>. Acesso em: 30 abr. 2021.

SANTOS, Miriã Cruz. Análise da distribuição espacial da arborização urbana no Bairro Jardim Rosa Branca em Jaú - SP. Revista Eletrônica de Tecnologia e Cultura, Jundiaí, v. 25, n. 25, p. 46-65, 2019.

SÃO PAULO. Prefeitura de São Paulo. Secretaria do Verde e do Meio Ambiente. Manual Técnico de Arborização Urbana. 2015. Disponível em:

<https://www.prefeitura.sp.gov.br/cidade/secretarias/upload/meio_ambiente/MANUALARBORIZACAO_22-01-15_.pdf >. Acesso em: 28 mar. 2021.

$\mathrm{SCHUCH}$, Maria lone Sarturi. Arborização urbana: uma contribuição à qualidade de vida com uso de geotecnologias. 2006. Dissertação (Mestrado em Geomática) - Universidade Federal de Santa Maria, Santa Maria, 2006. Disponível em:

<https://repositorio.ufsm.br/handle/1/9600>. Acesso em: 30 abr. 2021.

SOUZA, Mariana Cristina Cunha Souza.; AMORIM, Margarete Cristiane Costa Trindade. Qualidade ambiental em áreas verdes públicas na periferia de Presidente Prudente SP: os exemplos dos bairros Humberto Salvador e Morada do Sol. Caminhos de Geografia, Uberlândia, v. 17, n. 57, p. 59-73, 2016. Disponível em:

<http://www.seer.ufu.br/index.php/caminhosdegeografia/article/view/29445>. Acesso em: 30 abr. 2021.

TADENUMA, Sandra Stoker Kremer. Espacialização da arborização de vias públicas por densidade e níveis de atenção na área urbana de Ponta Grossa (PR). 2019. Dissertação (Mestrado em Gestão do Território) - Universidade Estadual de Ponta Grossa, Ponta Grossa, 2019. Disponível em <https://tede2.uepg.br/jspui/handle/prefix/3037>. Acesso em: 30 abr. 2021.

Recebido: dezembro de 2020. Aceito: maio de 2021. 